\title{
WILEY-VCH
}

\section{Functional Coatings on High-Performance Polymer Fibers for Smart Sensing}

Henning Galinski, Daniel Leutenegger, Martin Amberg, Fabio Krogh, Volker Schnabel, Manfred Heuberger, Ralph Spolenak, Dirk Hegemann*

Dr. D. Hegemann, M. Amberg, Prof. M. Heuberger

Empa, Swiss Federal Laboratories for Materials Science and Technology, Advanced Fibers, 9014 St.Gallen, Switzerland

E-mail: dirk.hegemann@empa.ch

Dr. H. Galinski, D. Leutenegger, Dr. F. Krogh, Dr. V. Schnabel, Prof. R. Spolenak ETH Zurich, Department of Materials, Laboratory for Nanometallurgy, 8093 Zurich, Switzerland

Keywords: thin film interference; color change; fiber tenacity; passive sensor; phase change media

Above a critical temperature, high performance fibers may lose their mechanical properties resulting in catastrophic events of damage when, e.g., used as load-carrying ropes. Here, we introduce a method to functionalize polymer fibers with thermochromic optical coatings that enable signaling of damaging thermal history. These smart coatings are comprised of an index-tunable anti-reflection coating based on chalcogenide phase change materials (PCM). We demonstrate that the insulator-metal phase transition of these materials can be aligned with the critical deterioration temperature of both polyethylene terephthalate (PET) monofilaments and liquid-crystal polyester (LCP) yarns by composition tuning. The carefully designed optical system amplifies the change in optical properties of its constituents upon phase change. The thermal and mechanical degradation of these fibers can thus be monitored and displayed by eye.

This document is the accepted manuscript version of the following article: Galinski, H., Leutenegger, D., Amberg, M., Krogh, F., Schnabe1, V., Heuberger, M., ... Hegemann, D. (2020). Functional coatings on high-performance polymer fibers for smart sensing. Advanced Functional Materials, 1910555 (6 pp.). https://doi .org/10.1002/adfm. 201910555 


\section{Introduction}

Synthetic fibers consist of uniaxially oriented, semicrystalline polymers that are spun into filaments exhibiting high tensile strength and tenacity ${ }^{1}$. These fibers can be used in a variety of applications ranging from textiles to load-carrying elements in ropes, belts and nets. ${ }^{[1,2]}$ Polyester fibers, the most widely used type of polymer fibers with a tenacity of up to about $0.8 \mathrm{~N} \mathrm{tex}^{-1}$ (high-tenacity polyester), exhibit a long lifetime of $>10^{5}$ cycles under cyclic loading conditions $\left(20^{\circ} \mathrm{C}, 65 \%\right.$ relative humidity (R.H.)), given the maximum load stays below $70 \%$ of the breaking strength. ${ }^{[3,4]}$ The breaking strength, however, can irreversibly drop when (unloaded) fibers are momentarily heated to elevated temperatures. ${ }^{[5]}$ For example, a polyethylene terephthalate (PET) monofilament can lose about $10 \%$ of its tenacity measured at ambient temperature after thermal exposure to $160^{\circ} \mathrm{C}$ for $1 \mathrm{~h}$, since dimensional stability and crystallinity start to change above $150^{\circ} \mathrm{C} .{ }^{[6,7]}$ In contrast, simultaneous mechanical and thermal loading of PET fibers results in a continuous strength reduction to about $50 \%$ tenacity retention at $180^{\circ} \mathrm{C}$ due to plastic deformation and creep rupture. ${ }^{[8,9]}$ Likewise, high-tenacity fibers such as Vectran ${ }^{\circledR}$, a liquid-crystal polymer made of an aromatic polyester (LCP) with a tenacity of $\sim 2 \mathrm{~N} \mathrm{tex}^{-1}$, and $\operatorname{Kevlar}^{\circledR}$, a heat-resistant aramid with a comparable tenacity to $\operatorname{Vectran}^{\circledR}$, show a strength retention of $85 \%$ and $70 \%$ following thermal exposure at $260^{\circ} \mathrm{C}$ for $24 \mathrm{~h}$, respectively. Their strength retention at simultaneous mechanical and thermal loading is again considerably lower. ${ }^{[10]}$ In case of Vectran ${ }^{\circledR}$, heat exposure should not exceed $300^{\circ} \mathrm{C}$ due to enhanced crystal-disordering processes leading to mechanical failure. ${ }^{[11]}$ Hence, for some applications it is imperative to diagnose if a rope has been exposed to high temperatures in order to avoid a serious event of damage.

\footnotetext{
${ }^{1}$ Tenacity is a specific strength defined as breaking force divided by linear density with units $1 \mathrm{~N}^{-1}=1000 \mathrm{Nm}$ $\mathrm{g}^{-1}=10^{6} \mathrm{~m}^{2} \mathrm{~s}^{-2}$ corresponding to $11.33 \mathrm{~g} \mathrm{den}^{-1}(1 \mathrm{den}=1 \mathrm{~g}$ per $9000 \mathrm{~m} ; 1$ tex $=1 \mathrm{~g}$ per $1000 \mathrm{~m})$.
} 


\section{WILEY-VCH}

Typically, in situ thermal monitoring of high performance fibers is achieved by integrating conductive fibers or optical fibers, in textile structures or cables. ${ }^{[12-14]}$ This active monitoring, however, requires a power supply or a light source. For many applications such active monitoring is not feasible. For example, load carrying ropes or guide and safety ropes used by fire fighters (Fig. 1a-c) demand for passive smart sensors for prompt in-place inspection, e.g. to display and locate a critical peak temperature history.

To address these challenges, we propose here a thermal monitoring concept that relies on passive low-footprint thermochromic optical coatings. Thermochromism is defined as the ability of materials to change their optical properties, e.g. its refractive index, as function of temperature ${ }^{[15]}$ In solids, this transition in materials properties can be induced by chemistry, e.g. oxidation or reduction. An alternative route is structural transformations, i.e. the transition from one crystallographic phase of the material to another. Prominent optical phase change materials (PCM)s are vanadium dioxide ${ }^{[16,17]}$ and chalcogenide compounds such as $\operatorname{AgInSbTe}{ }^{[18]}$ and GeSbTe $(\mathrm{GST}){ }^{[19]}$ but also metastable composites, such as TiAlN are used. ${ }^{[20]}$ These materials have been successfully applied as active strong interference coatings, ${ }^{[20-22]}$ active metasurfaces, ${ }^{[23-26]}$ and metalenses. ${ }^{[27,28]}$

In this work, we utilize phase changing germanium antimony tellurium (GST) compounds as functional coatings on PET and Vectran ${ }^{\circledR}$ fibers. GST exhibits an optical insulator-metal transition whose transition temperature can be controlled by changes in composition in a large window between $100^{\circ} \mathrm{C}-400^{\circ} \mathrm{C} .{ }^{[29,30]}$ Consequently, GST can be thermally converted from a dielectric to plasmonic material, as illustrated in Figure $1 \mathrm{f}$ and $1 \mathrm{~g}$. By embedding GST in a quarter-wave anti-reflection coating, this phase transition can be utilized to build a thermoresponsive display element that changes its color when heated across the phase transition temperature (Figure 1e). 


\section{WILEY-VCH}

a

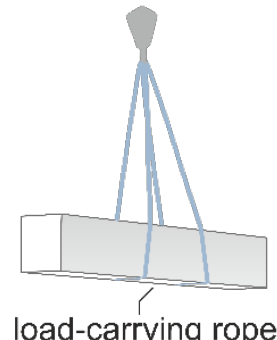

b

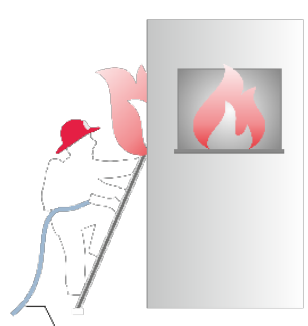

safety rope d
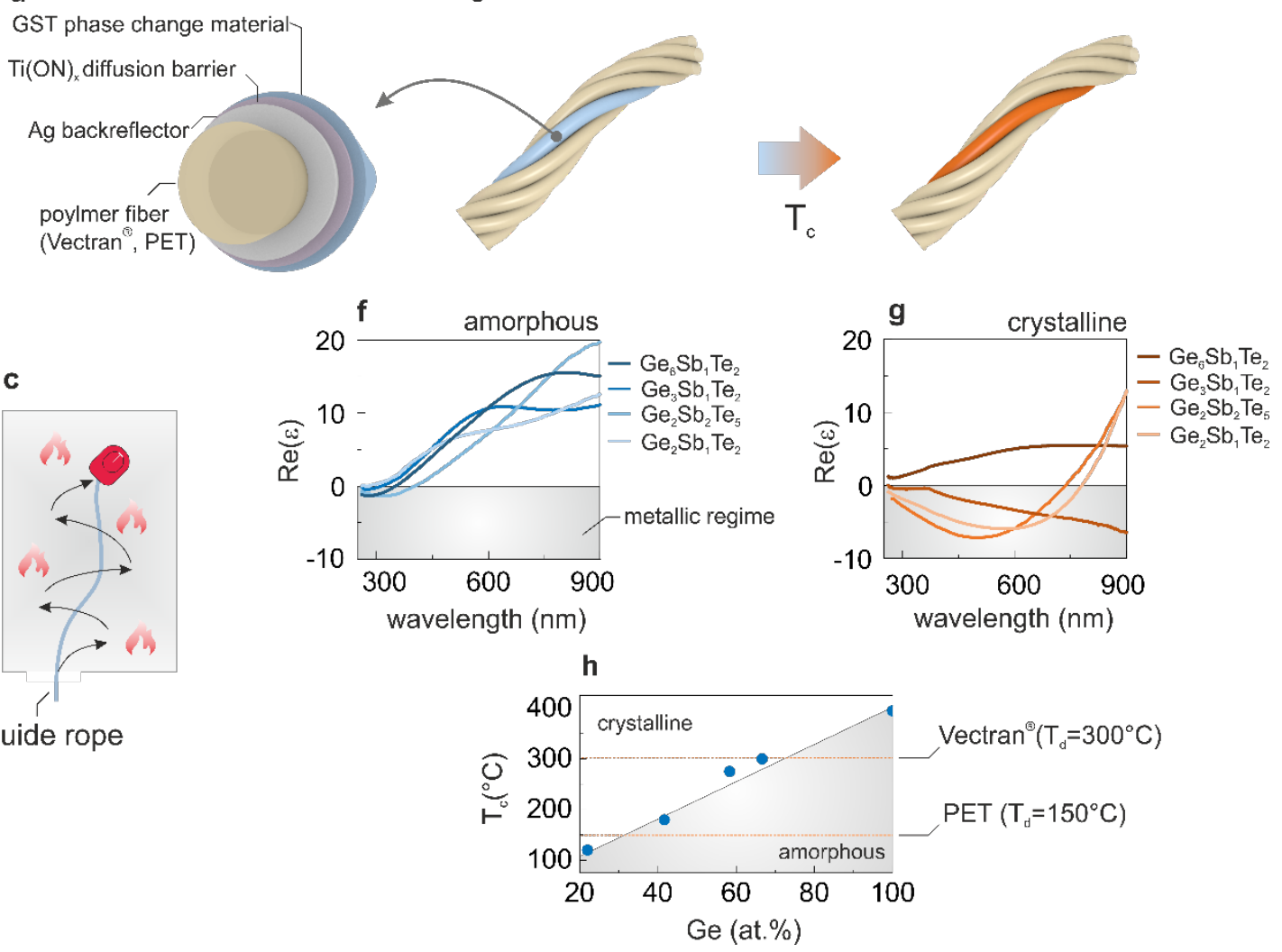

Figure 1. (a)-(c) Fields of application for high performance fibers comprising load-carrying ropes, safety or guide ropes used by fire fighters, where the detection of overexposure to heat is crucial. (d) Schematic illustration of the architecture and different components of the functionalized synthetic polymer fibers developed here. (e) Working principle of a thermochromic functionalized fiber bundle. When exceeding a critical temperature $T_{c}$ the phase transition in the GST layer induces a change in structural coloration. (f)-(g) Real part of the dielectric function for all examined GST coatings in the as-deposited and annealed state. $\mathrm{Ge}_{6} \mathrm{Sb}_{1} \mathrm{Te}_{2}$ exempted, the phase change from amorphous to crystalline causes also an insulator-to-metal transition, i.e. $\operatorname{Re}(\varepsilon)>0$ to $\operatorname{Re}(\varepsilon)<0$. (h) Phase transition temperatures $T_{\mathrm{c}}$ determined by ellipsometry and XRD measurements for different GST compounds. $\mathrm{T}_{\mathrm{c}}$ reveals a linear dependence on Ge content in the GST coatings. The deterioration temperature of PET and Vectran ${ }^{\circledR}$ fibers is indicated for comparison (orange dashed lines).

The architecture of the functionalized fibers used in this work is presented in Figure 1d. It comprises the polymeric fibers as core, and a three-layered quarter-wave anti-reflection coating that combines a metallic back-reflector, a dielectric diffusion barrier and an indextunable GST layer. A previously developed pilot plant reel-to-reel sputtering device was used 


\section{WILEY-VCH}

to deposit these optical coatings on PET monofilaments and Vectran ${ }^{\circledR}$ yarn. ${ }^{[31,32]} \mathrm{A}$ few kilometers of GST-coated fibers have been produced allowing upscaling to industrial processing.

\section{Results and Discussion}

\subsection{Optical insulator-to-metal transition in GST compounds}

To identify the GST compounds that align best with the deterioration temperature of the fibers, GSTs with different compositions have been deposited on flat substrates in a first step. Using the two target materials, $\mathrm{Ge}_{2} \mathrm{Sb}_{2} \mathrm{Te}_{5}$ and $\mathrm{Ge}_{6} \mathrm{Sb}_{1} \mathrm{Te}_{2}$, different GST compounds were deposited to examine the effect of composition on the phase transition temperature, $\mathrm{T}_{\mathrm{c}}$. Besides sputtering from the single targets, co-sputtering was utilized, while the target power has been varied to enlarge the range of compositions. Rutherford backscattering (RBS) and energy dispersive X-ray spectroscopy (EDX) measurements were employed to measure the chemical film composition of these films. In all, several GST compounds namely $\mathrm{Ge}_{2} \mathrm{Sb}_{2} \mathrm{Te}_{5}$, $\mathrm{Ge}_{6} \mathrm{Sb}_{1} \mathrm{Te}_{2}, \mathrm{Ge}_{2} \mathrm{Sb}_{1} \mathrm{Te}_{2}$, and $\mathrm{Ge}_{3} \mathrm{Sb}_{1} \mathrm{Te}_{2}$ were fabricated. The dielectric functions for all examined GST coatings were measured in the as-deposited (amorphous) and annealed (crystalline) state using ellipsometry. The real part $\operatorname{Re}(\varepsilon)$ of as-deposited and annealed GST films is displayed in Figure 1f and $1 \mathrm{~g}$, respectively.

The optical properties of all as-deposited GST compositions presented in Figure $1 \mathrm{f}$ are very similar and exhibit dielectric behavior indicating similar amorphous ordering. ${ }^{[33]}$ Conversely, in the annealed state, shown in Figure $1 \mathrm{~g}, \mathrm{Ge}_{2} \mathrm{Sb}_{2} \mathrm{Te}_{5}, \mathrm{Ge}_{2} \mathrm{Sb}_{1} \mathrm{Te}_{2}$ and $\mathrm{Ge}_{3} \mathrm{Sb}_{1} \mathrm{Te}_{2}$ feature metallic behavior with a negative refractive index, i.e. $\operatorname{Re}(\varepsilon)<0$, for wavelengths between 300 and $700 \mathrm{~nm}$. 


\section{WILEY-VCH}

Quite interestingly, we found that this insulator-to-metal transition depends on the Ge content. In the current temperature range only compounds with a Ge content $<60 \%$ exhibit this transition, while $\mathrm{Re}(\varepsilon)$ of $\mathrm{Ge}_{6} \mathrm{Sb}_{1} \mathrm{Te}_{2}$ films remained positive (Figure 1g).

The linked enhancement in free carriers can be attributed to Ge vacancies formed in the annealed structure, which turn the material into a degenerated semiconductor with a stronger metallic than semiconducting behavior. ${ }^{[34]}$ This effect, called resonant bonding, ${ }^{[35]}$ provides free carriers, which only occur if the atoms are ordered in a crystalline state. ${ }^{[36]}$. Phase-change materials such as GST films were reported to show a fast crystallization at the critical temperature. ${ }^{[37]}$ The color can rapidly switch due to the first-order transition from amorphous to crystalline phases. ${ }^{[22,38]}$

The critical temperature $T_{c}$ of those films was determined using the change in the dielectric constant $\varepsilon$ upon annealing, which was confirmed by XRD measurements for $\mathrm{Ge}_{2} \mathrm{Sb}_{2} \mathrm{Te}_{5}$ films . Plotting $T_{c}$ as a function of the Ge content of the different GST compositions including pure Ge films, a linear dependence was observed (Figure 1h). This is an important result, as it confirms that we can control $\mathrm{T}_{\mathrm{c}}$ within a large temperature range $\left(100-400^{\circ} \mathrm{C}\right)$. Furthermore, we can use $\mathrm{Ge}_{2} \mathrm{Sb}_{2} \mathrm{Te}_{5}$ and $\mathrm{Ge}_{6} \mathrm{Sb}_{1} \mathrm{Te}_{2}$ to functionalize our fibers, as $\mathrm{T}_{\mathrm{c}}$ of these compounds aligns well with the deterioration temperatures of PET and Vectran ${ }^{\circledR}$ fibers, respectively (Figure 1h).

\subsection{Thermo-responsive GST coatings on flat substrates}

To select the optical coatings best suited as thermo-responsive display element, several optical coatings based on $\mathrm{Ge}_{2} \mathrm{Sb}_{2} \mathrm{Te}_{5}$ and $\mathrm{Ge}_{6} \mathrm{Sb}_{1} \mathrm{Te}_{2}$ have been fabricated on Si wafers. The color difference between their as-deposited and annealed states has been analyzed. Figure 2a displays optical micrographs of $16 \mathrm{~nm}$ thick $\mathrm{Ge}_{2} \mathrm{Sb}_{2} \mathrm{Te}_{5}$ directly deposited on Au-coated $\mathrm{Si}$ wafers and annealed at different temperatures from 100 to $180^{\circ} \mathrm{C}$. The optical coatings exhibit a transition in coloration from a saturated blue to white metallic when heated above $130^{\circ} \mathrm{C}$. 


\section{WILEY-VCH}

The change in coloration is indicative of the phase transition in GST and an increase in free carriers. This behavior is also reflected in the measured reflectance spectra (Figure $2 \mathrm{~d}$ ) as the optical response is changed from an absorber with reflection dip in the red to a broad-band reflector.

To omit $\mathrm{Au}$ as back-reflector, $\mathrm{Ag}$ passivated by $\mathrm{Ti}(\mathrm{ON})_{\mathrm{x}}$ was examined as a cost-effective alternative. A $20 \mathrm{~nm}$ thick dielectric $\mathrm{Ti}(\mathrm{ON})_{\mathrm{x}}$ layer $(\mathrm{TiN} / \mathrm{TiON}$ 60:40 as characterized by Xray photoelectron spectroscopy (XPS)) was deposited to cover the Ag coating and restrict interdiffusion of $\mathrm{Ag}$, thus stabilizing the optical interference system. ${ }^{[39]} 18 \mathrm{~nm} \mathrm{Ge} \mathrm{Sb}_{2} \mathrm{Te}_{5}$ sputtered on this system also revealed a transition in coloration from sky blue to white metallic at a slightly higher temperature of $150^{\circ} \mathrm{C}$ (Figure 2b). The reflectance spectra reported in Figure 2e show the same characteristics as the GST/TiN ${ }_{x} / A u$ system (Figure 2d). ${ }^{[22]}$ Quite interestingly, the physics of these two optical coatings are slightly different. The $\mathrm{GST} / \mathrm{Ti}(\mathrm{ON})_{\mathrm{x}} / \mathrm{Ag}$ system, on one hand, operates as a reflective quarter-wave plate, where light reflected at the surface and at the $\operatorname{Ti}(\mathrm{ON})_{\mathrm{x}} / \mathrm{Ag}$ interface destructively interferes. The GST/Au system, on the other hand, utilizes the so-called strong interference effect ${ }^{[40,41]}$ based on absorption and a nontrivial phase change at the reflective layer. In general, GST/Ti(ON) $/ \mathrm{Ag}$ proved to be a suitable optical coating, thus Ag was used as metallic back-reflector for further investigations.

The thermochromicity observed in Figure $2 \mathrm{c}$ for $\mathrm{Ge}_{6} \mathrm{Sb}_{1} \mathrm{Te}_{2}$ based coatings is different. As the $\mathrm{Ge}_{6} \mathrm{Sb}_{1} \mathrm{Te}_{2}$ compound exhibits no insulator-metal transition during the crystalline-amorphous phase transition, the coloration of this antireflection coating gradually changes from blue to orange with increasing annealing temperature. This effect is also reflected in the measured reflectance spectra presented in Figure 2f. The reflectance minimum observed in the spectra continuously blue-shifts due to a decrease in refractive index for wavelengths larger than 450 $\mathrm{nm}$. This transition between two reflectance states, characterized by their respective reflectance minima (Figure $2 \mathrm{~g}$ ), is indicative of a second-order phase transition. ${ }^{[20]}$ Here, this 


\section{WILEY-VCH}

transition shown also in Figure $2 \mathrm{~g}$ occurs at $295^{\circ} \mathrm{C}$. The highest amorphous-to-crystalline phase transition temperature within the GST system is given by pure Ge films with $T_{c}$ above $380^{\circ} \mathrm{C} \cdot{ }^{[42]}$
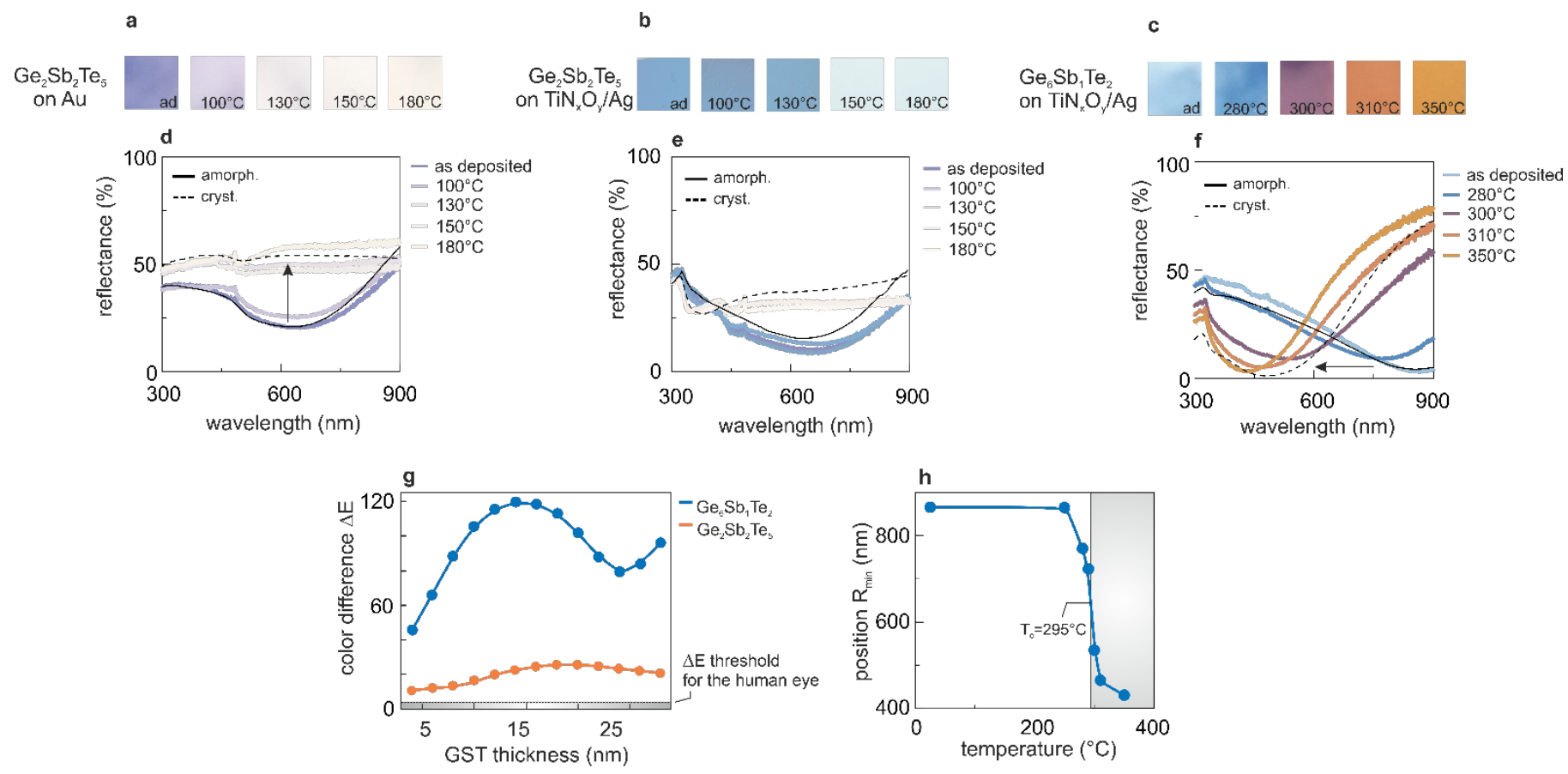

Figure 2. (a)-(c) Photographs taken at ambient light of (a) $16 \mathrm{~nm} \mathrm{Ge}_{2} \mathrm{Sb}_{2} \mathrm{Te}_{5}$, (b) $18 \mathrm{~nm}$ $\mathrm{Ge}_{2} \mathrm{Sb}_{2} \mathrm{Te}_{5}$, and (c) $22 \mathrm{~nm} \mathrm{Ge} 6 \mathrm{Sb}_{1} \mathrm{Te}_{2}$ based optical coatings deposited on flat $\mathrm{SiO}_{2} / \mathrm{Si}$ substrates covered with Au or passivated Ag. Each row displays the as-deposited initial state (ad) and the observed color change around the transition temperature. Annealing time was kept constant at 5 min. (d)-(f) Measured and calculated (black lines) reflectance using the transfer-matrix method of GST-based optical coatings for different annealing temperatures around the insulator-metal transition temperature. For $\mathrm{Ge}_{2} \mathrm{Sb}_{2} \mathrm{Te}_{5}$ the insulator-metal transition induces a stark color change (arrow) from blue to white metallic, whereas for $\mathrm{Ge}_{6} \mathrm{Sb}_{1} \mathrm{Te}_{2}$ the crystalline-amorphous phase transition does not cause a transition into the metallic regime. Thus, the color changes continuously as a result of the blue-shifting (arrow) reflectance minimum. (g) Measured color difference $\Delta \mathrm{E}$ between the as-deposited and annealed optical coatings as function of GST thickness. The critical $\Delta \mathrm{E}$ required for the human eye to see a color difference is indicated (shaded region). (h) Thermally induced blueshift of the reflectance minimum, observed in (f). The behavior is characteristic for a secondorder phase transition with a critical temperature of $\mathrm{T}_{\mathrm{c}}=295^{\circ} \mathrm{C}$. 


\section{WILEY-VCH}

The observed color changes on flat substrates upon annealing as well as the calculation of the dielectric function in the visible range thus corroborated that GST alloys can be used to build passive sensors displaying temperature-sensitive color changes at a desired $\mathrm{T}_{\mathrm{c}}$. Measuring the distance between the two colors given by their color difference $\Delta \mathrm{E},{ }^{[43]}$ a distinct $\Delta \mathrm{E}>80$ can be noted for $5-30 \mathrm{~nm}$ thick $\mathrm{Ge}_{6} \mathrm{Sb}_{1} \mathrm{Te}_{2}$ films. $\mathrm{Ge}_{2} \mathrm{Sb}_{2} \mathrm{Te}_{5}$ reaches a maximum of $\Delta \mathrm{E} \approx 25$ for $15-20 \mathrm{~nm}$ thick films, which is still clearly perceptible for the human eye requiring a minimum $\Delta \mathrm{E}$ of 3-4 (Figure $2 \mathrm{~g}$ ).

\subsection{Thermo-responsive GST coatings on fibers}

So far, the fabrication of the used thermo-responsive coatings was conducted on flat substrates. Therefore, it needs to be proved that the color change also works on curved surfaces such as polymer fibers. ${ }^{[44]}$ Based on the previously developed reel-to-reel sputtering process we first deposited smooth and electrically conductive Ag coatings on fibers. ${ }^{\text {[5] }}$ Passivating Ti(ON) (using a Ti target with $\mathrm{N}_{2}$ ) and GST layers (using $\mathrm{Ge}_{2} \mathrm{Sb}_{2} \mathrm{Te}_{5}$ and $\mathrm{Ge}_{6} \mathrm{Sb}_{1} \mathrm{Te}_{2}$ targets, respectively) were successively deposited on the highly reflective metallized fibers (Figure 3a). The fiber transport system guiding the fibers via multiple passes in front of the target ensured uniform coating along the fibers (Figure 3b) allowing the processing of $>1 \mathrm{~km}$ fiber in one run. $\mathrm{Ge}_{2} \mathrm{Sb}_{2} \mathrm{Te}_{5}$ and $\mathrm{Ge}_{6} \mathrm{Sb}_{1} \mathrm{Te}_{2}$ layers were selected due to their transition temperature from the amorphous to the crystalline state of $\sim 150^{\circ} \mathrm{C}$ and $\sim 300^{\circ} \mathrm{C}$, respectively, according to critical temperatures using PET and Vectran ${ }^{\circledR}$ fibers. Tensile strength measurements demonstrated that PET and Vectran ${ }^{\circledR}$ fibers lost their mechanical properties upon exposure to temperatures above $\mathrm{T}_{\mathrm{C}}$ (for $1 \mathrm{~h}$ ), as measured when returned to ambient temperature (Figure 3c). The observed different temperature stabilities are related to the polymer structure of PET and $V_{\text {ectran }}{ }^{\circledR}$ yielding a different $T_{C}$ at which dimensional stability and crystallinity becomes strongly affected. ${ }^{[7,11]}$ The three-step coating procedure itself by magnetron sputtering did not noticeably interfere with the mechanical 


\section{WILEY-VCH}

properties of the fiber, thus agreeing with findings that PET fibers readily maintain their tensile strength in Ar plasma treatments. ${ }^{[46,47]}$ Directly tested at elevated temperature, however, Vectran ${ }^{\circledR}$ fibers did not retain their strength due to their thermoplastic characteristics, i.e. enhanced plastic deformation occurs with increasing temperature yielding reduced breaking strengths. ${ }^{[10]}$ Hence, the passive sensor might be mainly applicable when fibers, ropes etc. have been subjected to unintended temperature exposure without or at subcritical load. Different temperature exposures, however, could be indicated using fibers coated with varying GST compositions.
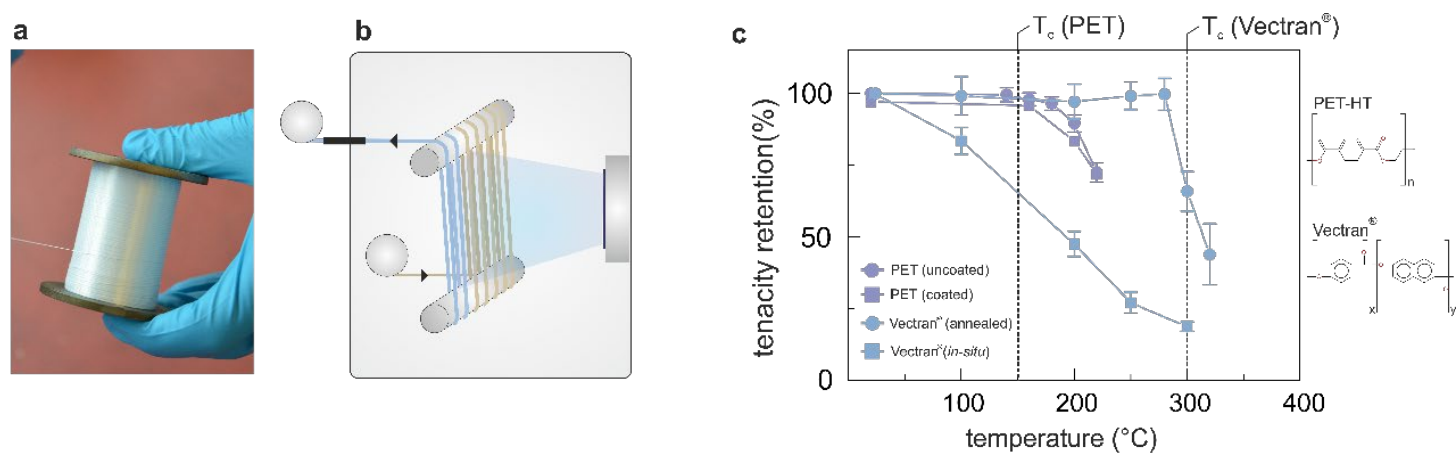

d
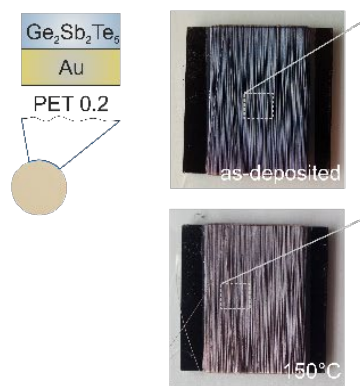
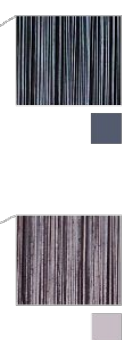

e

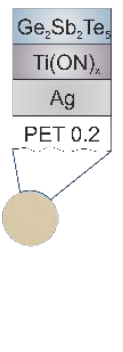

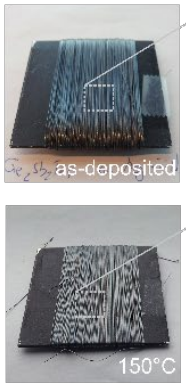

f
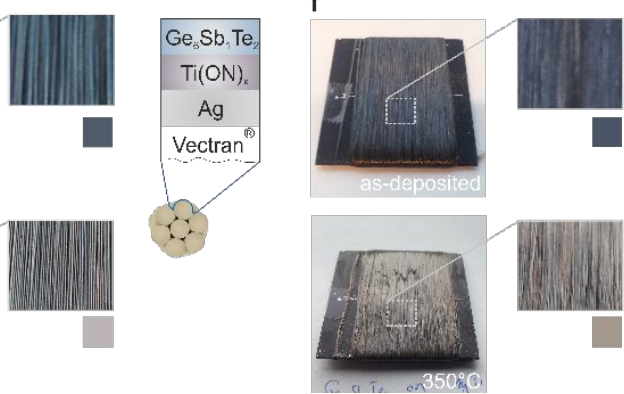

Figure 3. (a)-(b) Reel-to-reel processing of fibers guiding them several times through the plasma zone in front of the target material (Au, Ag, Ti, or GST). (c) Mechanical properties of uncoated and coated PET fiber as in (e) and Vectran ${ }^{\circledR}$ yarn as in (d) depending on annealing temperature (in-situ, post). The chemical structure of PET and Vectran ${ }^{\circledR}$ is indicated. (d)-(e) Optical appearance of coated PET fibers (monofilament), and (f) of Vectran ${ }^{\circledR}$ yarn (multifilament), as-deposited (ad) and once heated above the transition temperature $\mathrm{T}_{\mathrm{c}}$.

The initial silver shiny appearance of the Ag-coated fibers turned slightly yellowish with the passivating $\mathrm{Ti}(\mathrm{ON})_{\mathrm{x}}$ coating. The added semiconducting $\mathrm{Ge}_{2} \mathrm{Sb}_{2} \mathrm{Te}_{5}$ layer on PET 


\section{WILEY-VCH}

monofilament fiber gave a clear bluish color similar to the deposition on the Si wafer model substrates both with Au or passivated Ag as back-reflector (Figure 3d and 3e). This result demonstrates that the optical interference effect can also be achieved on the highly curved surfaces of a textile monofilament. Annealing of the PET monofilament fiber at a temperature above $150^{\circ}$, the $\mathrm{Ge}_{2} \mathrm{Sb}_{2} \mathrm{Te}_{5}$ layer changed its color into a whitish appearance within seconds, which demonstrates the usefulness as a critical peak temperature display.

The coated Vectran ${ }^{\circledR}$ yarn also showed a clearly perceptible color change when heated above $300^{\circ} \mathrm{C}$ (Figure $3 \mathrm{f}$ ). Different to flat substrates, however, the coating thickness is not uniform when deposited on a yarn, i.e. a fiber composed of many filaments, due to shadowing effects during sputtering. ${ }^{[48]}$ Therefore, the color appeared to be generally more whitish than might be expected and only faintly reddish after annealing. Anyhow, it was found that Ge-based optical interference systems can serve the purpose of irreversible operando temperature displays for high performance polymer fibers.

\section{Conclusion}

We have outlined and experimentally validated a path to deposit functional coatings on high performance fibers for smart sensing of thermal exposure. The applied thermochromic optical coatings rely on a thermally induced phase transition that can be aligned with the deterioration temperatures of PET monofilament fibers at $150^{\circ} \mathrm{C}$ and $\operatorname{Vectran}{ }^{\circledR}$ yarn at $300^{\circ} \mathrm{C}$. We demonstrate that when these fibers are heated above their deterioration temperature the optical coatings change their color indicating a critical overexposure to heat and enhanced risk of mechanical failure.

Such functionalized fiber architectures have been realized in a reel-to-reel process producing $>1 \mathrm{~km}$ of coated fibers, which demonstrated the general applicability for fiber production. 
Thus, these functionalized fibers can find numerous applications in smart ropes to indicate temperature exposures above different critical temperatures.

\section{Experimental Section}

Deposition on flat substrates: A high vacuum sputtering device (PVD Products) with a base pressure below $10^{-4} \mathrm{~Pa}$ was used to deposit coatings on Si wafers (100) using 3" targets (ETH Zurich system).$^{[22,41]}$ Rotation of the samples with 24 rounds per minute ensured uniform deposition. The magnetron sputtering was performed in Ar atmosphere (purity $>99.999 \%$ ) and the working pressure was kept to $0.67 \mathrm{~Pa}$. $\mathrm{Au}, \mathrm{Ag}$ (each $150 \mathrm{~nm}$ thick) and $\mathrm{Ti}(\mathrm{ON})_{\mathrm{x}}$ (with $10 \% \mathrm{~N}_{2}$ addition; $20 \mathrm{~nm}$ thick)) coatings were sputtered with direct current (dc), while for $\mathrm{Ge}$, $\mathrm{Ge}_{2} \mathrm{Sb}_{2} \mathrm{Te}_{5}$ and $\mathrm{Ge}_{6} \mathrm{Sb}_{1} \mathrm{Te}_{2}$ radio frequency (RF) current was applied (all targets with purities of at least $99.99 \%$ ). Co-sputtering using both $\mathrm{Ge}_{2} \mathrm{Sb}_{2} \mathrm{Te}_{5}$ and $\mathrm{Ge}_{6} \mathrm{Sb}_{1} \mathrm{Te}_{2}$ targets enabled the deposition of GST films with intermediate compositions.

The thicknesses of the individual layers were measured by X-ray reflectometry (XRR) with a PANalytical's $\mathrm{X}^{\prime} \mathrm{Pert}^{3}$ diffractometer and by Rutherford backscattering spectrometry (RBS) at the PSI/ETH EN tandem accelerator. For the latter, a ${ }^{4} \mathrm{He}^{+}$beam with 2 and $5 \mathrm{MeV}$, respectively, impinged on a sample and the energy of the backscattered particles was detected under an angle of $168^{\circ}$. Chemical composition was also characterized by RBS, by energy dispersive X-ray spectroscopy (EDX; Hitachi S-4800) with 10-20 kV accelerating voltage as well as by XPS (PHI VersaProbe II, Physical Electronics) using monochromatic Al Ka radiation $(1486.6 \mathrm{eV})$ at a take-off angle of $45^{\circ}$.

Reflectance measurements were performed with a fiber spectrometer (Ocean Optics DH2000-BAL) at an incident angle of $0^{\circ}$. The used deuterium and halogen lamps covered a range between 220 and $1020 \mathrm{~nm}$ wavelength. 


\section{WILEY-VCH}

Annealing was performed in a Createc RTA oven under vacuum $\left(<10^{-3} \mathrm{~Pa}\right)$ by heating from room temperature to the preselected temperature (up to $500^{\circ} \mathrm{C}$ ) at a rate of $0.5^{\circ} \mathrm{C} \mathrm{s}^{-1}$. The reached temperature was then kept for five minutes.

Deposition on textile fibers: A different magnetron sputtering device 'Stiletto' (ST20-O-C-M, AJA international) with 2" inch targets was used for the fiber coating (Empa St.Gallen system). ${ }^{[31,32]}$ A home-made fiber winding system allowed the transport of fibers in front of the target by unreeling from a small bobbin inserted into the vacuum chamber. The fibers were winded up on a bobbin at atmosphere by means of a differential pumping system. The base pressure reached was below $10^{-3} \mathrm{~Pa}$. The $\mathrm{Au}, \mathrm{Ag}, \mathrm{Ti}, \mathrm{Ge}_{2} \mathrm{Sb}_{2} \mathrm{Te}_{5}$ and $\mathrm{Ge}_{6} \mathrm{Sb}_{1} \mathrm{Te}_{2}$ targets were pulsed with $100 \mathrm{kHz}$ for $8 \mu$ s (80\% duty cycle). Deposition of TiN was performed with a Ti target in Ar with $\mathrm{N}_{2}$ admixture at a partial pressure of $33 \%$. For $\mathrm{Au}$ and $\mathrm{Ag}$, the pressure was kept at $2 \mathrm{~Pa}$ during deposition, while it was $0.67 \mathrm{~Pa}$ for all other coatings. After sputtering of one coating, the fibers were put back into the sputtering chamber to deposit the next coating.

As textile fibers, PET monofilaments (Ø $0.2 \mathrm{~mm}$, titre $43.5 \pm 2$ tex, tenacity $0.43 \pm 0.04 \mathrm{~N}^{-}$tex ${ }^{1}$ ) and Vectran ${ }^{\circledR}$ HT yarn (80 filaments, titre $44 \pm 2$ tex, tenacity $2.0 \pm 0.2 \mathrm{~N}^{-1} \mathrm{x}^{-1}$ ) were used. The tensile strength was measured on a Zwick Z100 yarn testing machine equipped with a 1 $\mathrm{kN}$ load cell $\left(23^{\circ} \mathrm{C}, 65 \%\right.$ R.H. $)$. The textile fibers were loaded with a crosshead speed of 100 $\mathrm{mm} \mathrm{min}^{-1}$. The fibers were heated for $1 \mathrm{~h}$ in an oven at different temperatures, returned to ambient temperature and measured again. In addition, in-situ tensile tests of Vectran ${ }^{\circledR} \mathrm{HT}$ yarn were conducted between $25^{\circ} \mathrm{C}-300^{\circ} \mathrm{C}$. A screw-driven mechanical testing machine operated at constant crosshead displacement rate (corresponding to a sample strain rate of $10^{-3} \mathrm{~s}^{-1}$ ) was used to determine the breaking force of the fiber at a given temperature. Tenacity retention was calculated relative to the tenacity as determined before heat exposure. Annealing of the optical interference system on fibers was performed by a hot-air gun placed $5 \mathrm{~cm}$ above the sample and a nearby mounted thermocouple to record the sample temperature. 


\section{WILEY-VCH}

For sample preparation the fibers were wound parallel around an aluminum plate $\left(5 \mathrm{x} 5 \mathrm{~cm}^{2}, 1\right.$ $\mathrm{mm}$ in height).

Dielectric function: The dielectric constants of the deposited layers were determined by a spectroscopic ellipsometer M-2000F ${ }^{\mathrm{TM}}$ using reference samples with approximately $50 \mathrm{~nm}$ of the corresponding material sputtered on a silicon wafer. For that purpose, the samples were exposed to $45^{\circ}$ polarized light from a xenon arc lamp and $\Delta$ as well as $\Psi$ were measured upon reflection. The incident angle was altered between $64-72^{\circ}$ and 50 scans were averaged. With a model of the silicon wafer and references from the analyzed material, the refractive indexes $n$ and extinction coefficient $k$ were determined with a normal fit between 260 and $950 \mathrm{~nm}$. Available data for Ge were used as initial values for all semiconductor compositions. ${ }^{[49]}$ The real and imaginary parts of the dielectric constant $\varepsilon$ were calculated according to:

$$
\begin{aligned}
\operatorname{Re}(\varepsilon) & =n^{2}-k^{2} \\
\operatorname{Im}(\varepsilon) & =2 \cdot n \cdot k
\end{aligned}
$$

\section{Acknowledgements}

The authors thank the FIRST cleanroom team at the ETH Zurich for their support. H.G. thanks for support from ETH Research Grant ETH-47 18-1. We thank N. Spencer and the LSST (ETH Zurich) for access to the ellipsometer as well as P. Rupper and M. Hilber (Empa) for their support with XPS and tensile strength measurements. 


\section{WILEY-VCH}

References

[1] H. Jiang, W. W. Adams, R. K. Eby, in Materials Science and Technology, WileyVCH, Weinheim, Germany 2006, 597.

[2] T. F. Flory, J. Hearle, H. Mckenna, M. Parsey, in Proceedings of the OCEANS MTS/IEEE Conference, Washington, DC, USA 2015.

[3] A. R. Bunsell, J. W. S. Hearle, J. Appl. Polym. Sci. 1974, 18, 267.

[4] S. Adanur, Wellington Sears Handbook of Industrial Textiles, Technomic, Lancaster, USA 1995.

[5] S. Bourbigot, X. Flambard, Fire Mater. 2002, 26, 155.

[6] M. Lewin, J. Preston, Handbook of Fiber Science and Technology, Volume 2: High Technology Fibers, Taylor \& Francis, Milton Park, UK 1985.

[7] H. M. El-Dessouky, M. R. Mahmoudi, K. M. Yassien, C. A. Lawrence, Polym. Eng. Sci. 2008, 2329.

[8] D. L. G. Sturgeon, Proc. 1975 Flywheel Technol. Symp., Berkeley, USA 1975.

[9] C. Le Clerc, A. R. Bunsell, A. Piant, J. Mater. Sci. 2006, 41, 7509.

[10] D. E. Beers, J. E. Ramirez, J. Text. Inst. 1990, 81, 561.

[11] J. D. Menczel, G. L. Collins, S. K. Saw, J. Therm. Anal. Calorim. 1997, 49, 201.

[12] C. Fernandez-Valdivielso, I. R. Matias, F. J. Arregui, Sens. Actuators. A 2002, 101, 107.

[13] A. Ukil, H. Braendle, P. Krippner, IEEE Sens. J. 2012, 12, 885.

[14] L. M. Castano, A. B. Flatau, Smart Mater. Struct. 2014, 23, 053001.

[15] X. Liu, W. J. Padilla, Adv. Mater. 2016, 28, 871.

[16] J. B. Goodenough, Phys. Rev. 1960, 117, 1442.

[17] A. Zylbersztejn, N. F. Mott, Phys. Rev. B 1975, 11, 4383.

[18] Y. Y. Chang, L. H. Chou, Jpn. J. Appl. Phys. 2005, 44, 3042.

[19] A. L. Greer, N. Mathur, Nature 2005, 437, 1246. 


\section{WILEY-VCH}

[20] V. Schnabel, R. Spolenak, M. Doebeli, H. Galinski, Adv. Opt. Mater. 2018, 6, 1800656.

[21] F. F. Schlich, A. Wyss, H. Galinski, R. Spolenak, Acta Mater. 2017, 126, 264.

[22] F. F. Schlich, P. Zalden, A. M. Lindenberg, R. Spolenak, ACS Photonics 2015, 2, 178.

[23] A. Karvounis, B. Gholipour, K. F. MacDonald, N. I. Zheludev, Appl. Phys. Lett. 2016, 109, 051103.

[24] B. Gholipour, A. Karvounis, J. Yin, C. Soci, K. F. MacDonald, N. I. Zheludev, NPG Asia Mater. 2018, 10, 533.

[25] C. Wan, E. H. Horak, J. King, J. Salman, Z. Zhang, Y. Zhou, P. Roney, B. Gundlach,

S. Ramanathan, R. H. Goldsmith, M. A. Kats, ACS Photonics 2018, 5, 2688.

[26] J. Rensberg, S. Zhang, Y. Zhou, A. S. McLeod, C. Schwarz, M. Goldflam, M. Liu, J.

Kerbusch, R. Nawrodt, S. Ramanathan, D. N. Basov, F. Capasso, C. Ronning, M. A. Kats, Nanolett. 2016, 16, 1050 .

[27] Y. Chen, X. Li, Y. Sonnefraud, A. I. Fernandez-Dominguez, X. Luo, M. Hong, S. A. Maier, Sci. Rep. 2015, 5, 8660

[28] Q. Wang, E. T. F. Rogers, B. Gholipour, C. M. Wang, G. Yuan, J. Teng, N. I.

Zheludev, Nature Photonics 2016, 10, 60.

[29] V. Bragaglia, F. Arciprete, W. Zhang, A. M. Mio, E. Zallo, K. Perumal, A. Giussani, S. Cecchi, J. E. Boschker, H. Riechert, S. Privitera, E. Rimini, R. Mazzarello, R. Calarco, Sci. Rep. 2016, 6, 23843.

[30] V. Bragaglia, F. Arciprete, A. M. Mio, R. Calarco, J. Appl. Phys. 2018, 123, 215304.

[31] M. Amberg, P. Rupper, R. Storchenegger, M. Weder, D. Hegemann, Nanomed. Nanotechnol. Biol. Med. 2015, 11, 845.

[32] M. Amberg, A. Haag, R. Storchenegger, P. Rupper, F. Lehmeier, R.M. Rossi,

D. Hegemann, Sci. Technol. Adv. Mater. 2015, 16, 1.

[33] J. Akola, R. O. Jones, Phys. Status Solidi B 2012, 249, 1851. 


\section{WILEY-VCH}

[34] T. Siegrist, P. Merkelbach, M. Wuttig, Annu. Rev. Condens. Matter Phys. 2012, 3, 215.

[35] L. Pauling, The Nature of Chemical Bond and the Structure of Molecules Aid Crystals, Cornell Univ. Press, New York 1939.

[36] S. Lee, K. Esfarjani, T. Luo, J. Zhou, Z. Tian, G. Chen, Nat. Commun. 2014, 5, 3525.

[37] N. Yamada, E. Ohno, K. Nishiuchi, N. Akahira, M. Takao, J. Appl. Phys. 1991, 69, 2849.

[38] P. Hosseini, C. D. Wright, H. Bhaskaran, Nature 2014, 511, 206.

[39] D. Adams, B. A. Julies, J. W. Mayer, T. L. Alford, Thin Solid Films 1998, 332, 235.

[40] M. A. Kats, R. Blanchard, P. Genevet, F. Capasso, Nature Mater. 2013, 12, 20.

[41] F. F. Schlich, R. Spolenak, Appl. Phys. Lett. 2013, 103, 213112.

[42] A. Barna, P. B. Barna, J. F. Pocza, J. Non-Cryst. Solids 1972, 8-10, 36.

[43] J. B. Patel, R. S. Anand, IOSR J. Electron. Commun. Eng. 2012, 1, 24.

[44] M. A. Kats, F. Capasso, Appl. Phys. Lett. 2014, 105, 131108.

[45] D. Hegemann, M. Amberg, A. Ritter, M. Heuberger, Mater. Technol. 2009, 24, 41.

[46] M. O. H. Cioffi, H. J. C. Voorwald, V. Ambrogi, T. Monetta, F. Bellucci, L. Nicolais, J. Mater. Eng. Perform. 2003, 12, 279.

[47] M. Keller, A. Ritter, P. Reimann, V. Thommen, A. Fischer, D. Hegemann, Surf. Coat. Technol. 2005, 200, 1045.

[48] M. Amberg, M. Vandenbossche, D. Hegemann, Surf. Coat. Technol. 2018, 336, 29.

[49] G. E. Jellison, Opt. Mater. 1992, 1, 151. 